\title{
Evaluation of Intraperitoneal and Incisional Bupivacaine or Levobupivacaine for Postoperative Analgesia in Ovariohysterectomized Dogs
}

\author{
Musa Korkmaz' , Oktay Yilmaz², Zulfukar Kadir Saritas' ', Ibrahim Demirkan'1 \& Jerzy Jaroszewski³
}

\begin{abstract}
Background: Ovariohysterectomy (OHE) is the most commonly performed elective surgical procedure in companion animals. OHE offers benefits of control of population and decreased risk of potentially life-threatening diseases such as mammarian tumours and pyometra. Traditional OHE intervention causes inflammation and pain due to trauma during organ manipulation. The purpose of this study was to compare the effect of intraperitoneal and incisional administration of bupivacaine (BP) or levobupivacaine (LP) on postoperative analgesia in dogs undergoing the OHE procedure.

Materials, Methods \& Results: A total of 24 mix-breed bitches aged between 1 - 3 years and weighed 19 - $20 \mathrm{~kg}$ were used in this study. The animals were divided into three groups as control $(\mathrm{n}=8)$, BP $(\mathrm{n}=8)$ and LP group $(\mathrm{n}=8)$. The animals were kept under surveillance at the hospitalisation unit of the animal hospital for one day before the elective OHE. The dogs were fasted for $12 \mathrm{~h}$ before the surgery, with adlib water consumption. Atropine sulphate $0.045 \mathrm{mg} / \mathrm{kg}$ was administered subcutaneously approximately $30 \mathrm{~min}$ before general anaesthesia. Midazolam $(0.3 \mathrm{mg} / \mathrm{kg})$ was intravenously injected into all dogs for pre-anaesthetic medication. After sedation, anaesthesia was induced with propofol (4 mg/kg, IV) and then the dogs were orotracheally intubated using cuffed endotracheal tubes. General anaesthesia was maintained by administration of $2 \%$ isoflurane. The ventral abdomen was prepared aseptically for OHE following the general anaesthesia. All animals were operated on by the same surgeon. During surgery, sprayed bupivacaine $0.5 \%(4.4 \mathrm{mg} / \mathrm{kg})$ with an equal volume of saline in BP group, levobupivacaine $0.5 \%(4.4 \mathrm{mg} / \mathrm{kg})$ with an equal volume of saline in LP were then applied over the ovaries, uterine broad ligaments and cervix uteri. After removal of the uterine body, either LP or BP was sprayed to left and right, or cranial and caudal parts of the abdominal cavity. Finally, the incision line was sprayed before closing the skin. The control group received only sprayed saline. The pain evaluation was carried out with modified Melbourne pain scoring scale. To determine cortisol concentrations, blood samples were taken before anaesthesia induction (baseline) and postoperative $0,0.5,1,2,4,6,12$ and $24 \mathrm{~h}$. Postoperative pain scores were higher in the control group than BP and LP groups following surgery at $30 \mathrm{~min}, 1 \mathrm{st}, 4 \mathrm{th}$, and 6th $\mathrm{h}$. In all groups, cortisol levels increased postoperatively, whereas they decreased more rapidly in BP and LP groups. There was a steady increase at postoperative $0 \mathrm{~min}, 30 \mathrm{~min}, 1 \mathrm{st}, 2 \mathrm{nd}$, 4th and 6th $\mathrm{h}$ in the control group and at postoperative $0 \mathrm{~min}, 30 \mathrm{~min}$ and $1 \mathrm{~h}$ in BP and LP groups $(P<0.05)$.

Discussion: Intraperitoneal and incisional bupivacaine shows significantly superior postoperative pain management benefits after the closure of skin, compared to untreated dogs and it is also superior to lidocaine treatment at $0.5 \mathrm{~h}$ following the visual analogy pain assessment system. In the present study, the observation of lower pain scores in BP group at $0.5,1,4$ and $6 \mathrm{~h}$ as compared to the control group was similar to findings of other studies. LP group also showed decreased pain scores at above-mentioned hours without any significant difference. However, only in LP group, pain scores at $24 \mathrm{~h}$ were lower than postoperative pain scores. In conclusion, it is suggested that sprayed intraperitoneal and incisional BP and LP are very effective for preventing postoperative pain ovariohysterectomized dogs.
\end{abstract}

Keywords: bupivacaine, dog, levobupivacaine, postoperative analgesia, pain management. 


\section{INTRODUCTION}

Ovariohysterectomy (OHE) is the most commonly performed elective surgical procedure in companion animals [25,31]. OHE offers benefits of control of population and decreased risk of potentially life-threatening diseases such as mammarian tumours and pyometra [24]. Traditional OHE intervention causes inflammation and pain due to trauma during organ manipulation $[2,14,19,21]$. Tissue injury during surgical procedures is associated with pain. Therefore the management of perioperative pain is highly recommended for controlling pain responses to reduce complications and improve the quality of recovery [30].

Inexpensive, easily available and applicable local anaesthetics have been widely used epidurally, intraarticularly, perineurally or intraperitoneally in veterinary and human medicine to prevent or relieve pain $[1,6,17,18,28]$. Bupivacaine (BP) is a long-acting amino amide local anaesthetic agent $[5,20]$. The most important toxic effect of BP is cardiac depression. Accidental high intravenous doses may cause cardiac arrest and fatal arrhythmias [13,20]. To overcome these side effects, Levobupivacaine (LP) was developed alternatively to BP due to its low toxicity, however, the chemical structure, pharmacokinetic and pharmacodynamics traits of LP are similar to those of BP [10]. Previously, the effects of intraperitoneal and incisional BP [14,16] and lidocaine [4] have been reported. However, to the authors' knowledge, no study has reported the postoperative effect of incisional LP in dogs. Thus, the present study was performed to investigate the effect of intraperitoneal and incisional BP and LP on postoperative pain in dogs who have undergone OHE.

\section{MATERIALS AND METHODS}

\section{Animals}

A total of 24 mix-breed bitches aged between 1 - 3 years were used in this study. The animals were divided into three groups as control $(\mathrm{n}=8)$, BP $(\mathrm{n}=$ 8 ) and LP group $(n=8)$. The mean body weight was $20.1 \pm 4.6 \mathrm{~kg}$ in control group, $19.01 \pm 2.9 \mathrm{~kg}$ in BP group and $20.8 \pm 3.1 \mathrm{~kg}$ in LP group.

The animals were kept under surveillance at the hospitalisation unit of the animal hospital for one day before the elective OHE. The dogs were fasted for $12 \mathrm{~h}$ before the surgery, with ad libitum water consumption. An intravenous (IV) catheter was introduced into the cephalic vein of animals for anaesthetic induction, fluid administration and blood sample collection.

Anaesthesia procedure

Atropine sulphate $\left(\text { Atropin }^{\circledR}\right)^{1}[0.045 \mathrm{mg} / \mathrm{kg}]$ was administered subcutaneously approximately 30 min before general anaesthesia. Midazolam (Dormi$\left.\operatorname{cum}^{\circledR}\right)^{2}[0.3 \mathrm{mg} / \mathrm{kg}]$ was intravenously injected into all dogs for pre-anaesthetic medication. After sedation, anaesthesia was induced with propofol $\left(\text { Propofol }^{\circledR}\right)^{3}$ [4 mg/kg, IV] and then the dogs were orotracheally intubated using cuffed endotracheal tubes. General anaesthesia was maintained by administration of $2 \%$ isoflurane $\left(\text { Forane }^{\circledR}\right)^{4}$. Intravenous lactated Ringer's solution $[10 \mathrm{~mL} / \mathrm{kg} / \mathrm{h}]$ were provided throughout the procedure. All dogs were monitored (Petaş) $)^{5}$ for measuring heart beats and respiratory rates.

\section{Surgical procedure}

The ventral abdomen was prepared aseptically for OHE following the general anaesthesia. All animals were operated by the same surgeon. Accordingly, a ventral midline incision $(1.5-2.5 \mathrm{~cm})$ on the abdominal wall was performed. The linea alba was incised to reach the abdominal cavity. The uterine ligament was held by a uterine hook to hold the uterus. The cranial part of both ovaries and cervix uteri were ligatured. Local anaesthetics, 0.5\% BP (Marcaine $\left.{ }^{\circledR}\right)^{6}[4.4 \mathrm{mg} /$ $\mathrm{kg}]$ and $0.5 \%$ LP $\left(\text { Chirocaine }^{\circledR}\right)^{4}[4.4 \mathrm{mg} / \mathrm{kg}]$, were prepared using the equal volume of saline following calculation of the individual doses. The preparations were then sprayed over the ovaries, uterine broad ligaments and cervix uteri. After removal of the uterine body, either LP or BP was sprayed to left and right, or cranial and caudal parts of the abdominal cavity. Finally, the incision line was sprayed before closing the skin. The control group received only sprayed saline. The standard OHE procedure was performed in all dogs by an experienced gynaecologist. The durations of anaesthesia and surgery were recorded. Daily injections of penicillin + streptomycin $\left(\text { Penoksal }^{\circledR}\right)^{7}$ [20 $\mathrm{mg} / \mathrm{kg}$, IM] were given for five days during the hospitalisation process.

\section{Pain assessment and blood sampling}

Evaluation of pain in all dogs was assessed by the same person, who did not know which agent was sprayed or which groups were studied. Modified Melbourne Pain Scale (MMPS) was used for the evaluation 
of pain (Table 1) [23]. Pain scores were recorded at $0,0.5,1,2,4,6,12$, and $24 \mathrm{~h}$ after extubation. Blood samples were collected from vena cephalica antebrachium to measure serum cortisol concentrations before anaesthesia induction (baseline) and postoperative at 0 ,
$0.5,1,2,4,6,12$ and $24 \mathrm{~h}$. Samples were immediately centrifuged at $5000 \mathrm{rpm}$ for 10 minutes, and then sera were stored at $-20^{\circ} \mathrm{C}$ until further cortisol analysis using a commercial kit (Cortisol kit) ${ }^{2}$ by electrochemiluminescence immunoassay (Cobas e-411) ${ }^{2}$.

Table 1. Modified Melbourne Pain Scoring Scale according to Odete \& Smith [23].

$\begin{array}{cc}\text { Dog Name/ID: } & \text { Date: } \quad \text { Total UMPS Score: } \\ \text { Category and descriptor Score } & \text { Breed: }\end{array}$

From outside the cage

Vocalization (choose only one)*

Not vocalizing

Slight vocalization but dysphoric

Intermittent vocalization

Continuous vocalization

1

Posture

a) Guarding or protecting affected area

b) Position (choose only one)

Lateral recumbency

Sternal recumbency

Sitting, standing, or comfortable

Standing with head hanging

Moving

Abnormal posture and/or uncomfortable, continuous position change

Activity (choose one)

At rest

Sleeping

Semi-conscious

Awake

Eating

Restless (pacing continuously; getting up and down)

Rolling and thrashing

From inside the cage

Mental status (choose only one)** Baseline minus current score $=$ overall score

Too sedate to evaluate or dysphoric

Submissive

Uninterested in people (unusual for this dog)

Overtly friendly

Wary or Aggressive

Response to palpation (choose only one) ***

Normal, allows palpation of surgical site

0

1

2

1

Allows but then moves away, tenses or looks when surgical area touched 1

Increased whining or painful expression when surgical area touched 2

Will not allow general surgical area to be touched

Vocalization (choose only one)*

Not vocalizing

Vocalizing but responds to quiet voice and/or stroking

Vocalizing when touched

Intermittent vocalization

0

0

1

0

2

Continuous vocalization

The minimum possible score is 0 ; the maximum possible score is $20 . *$ Does not include alert barking. **For this category, score recorded is the score obtained after surgery minus the score obtained before surgery. ***Palpate around the general surgical area starting at the dorsal end and working toward incision site 
Butorphanol (Butomidor $\left.{ }^{\circledR}\right)^{8}[0.2 \mathrm{mg} / \mathrm{kg}$, i.v $]$ was given as a rescue analgesic at any time, when the MMPS was scored higher than 9 points. Additional butorphanol injection was given, if the rescue analgesic was necessary. The animals were observed for signs of BP or LP anaesthetic toxicity (i.e. tremors and seizures) during the postoperative process.

\section{Statistics}

Differences in pain scores and the concentrations of cortisol detected during measurement times between the groups, were compared using the analysis of variance (ANOVA) followed by Tukey test (SPSS 13.0), whereas a repeated measures ANOVA test was used to compare differences within the groups for serum cortisol and pain scores obtained at allocated times. Values were described by mean \pm Standard Deviation (SD). The data were considered to be significantly different at $P<0.05$.

\section{RESULTS}

The mean duration of anaesthesia was $28 \pm 4.8$ $\min , 26.8 \pm 2.9 \mathrm{~min}$ and $27.6 \pm 3.1 \mathrm{~min}$ in the control, BP and LP groups, respectively. The duration of surgery was $17 \pm 5.9 \mathrm{~min}, 17.2 \pm 6.9$ and $14 \pm 4.5 \mathrm{~min}$ in the control, BP and LP groups, respectively. There was no statistically significant difference between the duration of anaesthesia and the surgical procedure among the groups. Moreover, $1.5-2.5 \mathrm{~cm}$ length of skin incision line was performed and any unnecessary manipulations were avoided. Accordingly, the duration of anaesthesia and the surgical procedure did not show any significant difference between the groups.

The distribution of pain scores depending on time in groups is shown in Table 2. No animals were given any rescue analgesic due to the absence of animals that showed no pain score higher than 9 points. Postoperative pain scores were higher in the control group than those detected in the BP and LP groups at 0.5, 1, 4 and $6 \mathrm{~h}$ after the end of surgery, however these differences were not statistically significant. The pain scores were higher at $0.5,1,4$ and $6 \mathrm{~h}$ compared to other times in the control group, but not statistically significant. On the other hand, a statistically significant decline in the pain score was detected only at 24 $\mathrm{h}$ in the control group $(P<0.05)$. Moreover, it was found that the pain scores in BP and LP groups were similar to other allocated times and the decline in pain scores was statistically significant in both groups at $24 \mathrm{~h}(P<0.05)$.

The distribution of concentrations of cortisol in the groups is given in Table 3. It was determined that the concentrations of cortisol did not show any significant difference in all groups at baseline, postoperative 0,12 and $24 \mathrm{~h}$. The concentrations of cortisol at postoperative 0.5 and $1 \mathrm{~h}$ were lower in LP group than those detected in the control group $(P<0.05)$, whereas LP and BP groups did not display any significant difference at postoperative 0.5, 1, 2, 4 and $6 \mathrm{~h}$. However, the control group had higher cortisol concentrations at 2, 4 and $6 \mathrm{~h}$ compared to LP and BP groups $(P<0.05)$.

The concentrations of cortisol in the control group detected at postoperative $0,0.5,1,2,4$ and $6 \mathrm{~h}$ were higher than those measured at baseline values $(P$ $<0.05)$, and concentrations of cortisol measured at 12 and $24 \mathrm{~h}$ were similar to baseline concentrations $(P>$ $0.05)$. The concentrations of cortisol measured in BP group at postoperative $0,0.5$ and $1 \mathrm{~h}$ were higher $(P<$ $0.05)$ than the concentrations detected at baseline concentrations. The concentrations of cortisol measured at postoperative $0,0.5$ and $1 \mathrm{~h}$ were higher $(P<0.05)$ with respect to baseline values in LP group.

Table 2. Distribution of pain scores in ovariohysterectomized bitches treated with intraperitoneal and incisional saline, Bupivacaine and Levobupivacaine.

\begin{tabular}{cccc}
\hline $\begin{array}{c}\text { Pain scoring }(\mathrm{h}) \\
\text { Postoperative }\end{array}$ & Control $(\mathrm{n}=8)$ & Bupivacaine $(\mathrm{n}=8)$ & Levobupivacaine $(\mathrm{n}=8)$ \\
\hline 0 & $3.2 \pm 0.5^{\mathrm{ab}}$ & $2.8 \pm 0.3^{\mathrm{ab}}$ & $3.1 \pm 0.3^{\mathrm{a}}$ \\
0.5 & $3.5 \pm 0.9^{\mathrm{ab}}$ & $2.8 \pm 0.3^{\mathrm{ab}}$ & $3.0 \pm 0.5^{\mathrm{ab}}$ \\
1 & $3.8 \pm 1.3^{\mathrm{a}}$ & $3.0 \pm 0^{\mathrm{ab}}$ & $3.2 \pm 0.7^{\mathrm{a}}$ \\
2 & $3.0 \pm 0.9^{\mathrm{ab}}$ & $2.8 \pm 0.3^{\mathrm{ab}}$ & $3.1 \pm 0.3^{\mathrm{a}}$ \\
4 & $4 \pm 1.1^{\mathrm{a}}$ & $3.1 \pm 0.3^{\mathrm{ab}}$ & $3.2 \pm 0.7^{\mathrm{a}}$ \\
6 & $3.8 \pm 0.9^{\mathrm{a}}$ & $3.6 \pm 0.9^{\mathrm{a}}$ & $3.2 \pm 0.7^{\mathrm{a}}$ \\
12 & $3.2 \pm 0.7^{\mathrm{ab}}$ & $3.5 \pm 1.3^{\mathrm{ab}}$ & $3.1 \pm 0.8^{\mathrm{a}}$ \\
24 & $2.2 \pm 0.3^{\mathrm{b}}$ & $2.1 \pm 0.3^{\mathrm{b}}$ & $2.1 \pm 0.3^{\mathrm{b}}$ \\
\hline
\end{tabular}

${ }^{\mathrm{ab}}$ Different letters in same column indicate significant differences $(P<0.05)$ within groups. Pain scores did not show any significant difference between groups. [0.9\% saline, $0.5 \%$ Bupivacaine $(4.4 \mathrm{mg} / \mathrm{kg}$ b.w.) and $0.5 \%$ Levobupivacaine ( $4.4 \mathrm{mg} / \mathrm{kg}$ b.w.). Pain assessment was started at the end of surgery (postoperative)]. 
Table 3. Serum cortisol concentrations in ovariohysterectomized bitches treated with intraperitoneal and incisional saline, Bupivacaine and Levobupivacaine.

\begin{tabular}{|c|c|c|c|}
\hline Blood sampling (h) & Control $(n=8)$ & Bupivacaine $(\mathrm{n}=8)$ & Levobupivacaine $(\mathrm{n}=8)$ \\
\hline Baseline & $2.52 \pm 0.9^{\mathrm{e}}$ & $2.45 \pm 0.6^{c}$ & $3.22 \pm 0.8^{\mathrm{c}}$ \\
\hline Postoperative 0 & $8.96 \pm 3.1^{\mathrm{abc}}$ & $9.20 \pm 2.3^{\mathrm{a}}$ & $9.29 \pm 2.6^{\mathrm{a}}$ \\
\hline 0.5 & $10.86 \pm 2.6^{\mathrm{abA}}$ & $9.42 \pm 3.2^{\mathrm{aAB}}$ & $6.78 \pm 1.5^{\mathrm{bB}}$ \\
\hline 1 & $11.51 \pm 1.2^{\mathrm{aA}}$ & $8.22 \pm 4.2^{\mathrm{abAB}}$ & $6.41 \pm 1.2^{\mathrm{bB}}$ \\
\hline 2 & $9.87 \pm 2.2^{\mathrm{abA}}$ & $5.69 \pm 3.8^{\mathrm{abcB}}$ & $4.15 \pm 0.8^{\mathrm{cB}}$ \\
\hline 4 & $7.54 \pm 3.1^{\mathrm{bcdA}}$ & $4.11 \pm 1.9^{\mathrm{abcB}}$ & $3.52 \pm 1.1^{\mathrm{cB}}$ \\
\hline 6 & $6.08 \pm 2.3^{\mathrm{cdA}}$ & $3.79 \pm 1.4^{\mathrm{cB}}$ & $3.64 \pm 1.1^{\mathrm{cB}}$ \\
\hline 12 & $4.42 \pm 1.5^{\mathrm{de}}$ & $3.65 \pm 1.5^{\mathrm{c}}$ & $2.98 \pm 0.6^{c}$ \\
\hline 24 & $3.51 \pm 1.5^{\mathrm{e}}$ & $2.33 \pm 1.4^{\mathrm{c}}$ & $2.65 \pm 1.1^{\mathrm{c}}$ \\
\hline
\end{tabular}

Small $^{(\mathrm{abc})}$ and capital ${ }^{(\mathrm{AB})}$ letters in superscript indicate significant differences $(P<0.05)$ within the group and between the groups, respectively. [0.9\% saline, $0.5 \%$ Bupivacaine ( $4.4 \mathrm{mg} / \mathrm{kg}$ b.w.) and $0.5 \%$ Levobupivacaine ( $4.4 \mathrm{mg} / \mathrm{kg}$ b.w.). Samples were obtained at baseline and 0 , $0.5,1,2,4,6,12$, and $24 \mathrm{~h}$ following extubation].

\section{DISCUSSION}

The OHE procedure is a common and traumatic elective surgery in dogs, and it is associated with a various degree of inflammation [19]. Behavioural changes due to pain in spayed female dogs within $24 \mathrm{~h}$ after surgery have been reported elsewhere $[15,19,30]$. Therefore, OHE is a preferred surgical procedure for researchers, since it is a good surgical model to assess both postoperative pain, and the effects of analgesic agents $[8,21,22,26,27]$. The present study evaluated the effect of intraperitoneal and incisional BP and LP on postoperative pain in bitches which had elective OHE.

It was reported that experienced surgeons $(10$ years or more) perform the OHE in 13 to $28 \mathrm{~min}$ (17 min on average), while unpractised intern students have a longer duration of surgery, between 55 and 130 $\min$ (87 min on average). Elevated postoperative pain and increased blood cortisol levels were of concern in dogs that were operated on by students [22]. Devitt et al. [9] stated that the duration of standard OHE was $18.30 \pm 3.9 \mathrm{~min}$, whereas laparoscopic OHE was accomplished in $20.80 \pm 4.0 \mathrm{~min}$. The duration of OHE in our study was similar to above mentioned studies $[9,19,22]$ and none of the groups displayed any severe pain symptoms.

The achievement of effective intraperitoneal analgesia requires using a high volume of the local anaesthetic agent. This may cause dose-dependent manner side effects such as sedation, vomiting, tremors or seizures $[4,16]$. In our study we did not observed any side effects after BP and LP administration. Therefore, it is advisable that the local dose of $4.4 \mathrm{mg} / \mathrm{kg} \mathrm{BP}$ or LP may be beneficial to use during OHE surgery.

Intraperitoneal and incisional bupivacaine shows significantly superior postoperative pain management benefits after the closure of skin, compared to untreated dogs $[3,4,8]$ and it is also superior to lidocaine treatment at $0.5 \mathrm{~h}$ following the visual analogy pain assessment system. If the composite pain scoring system is used, the scores obtained by BP are significantly lower than those detected at $0.5 \mathrm{~h}$ in untreated dogs [4]. In the present study, the observation of lower pain scores in BP group at 0.5, 1, 4 and $6 \mathrm{~h}$ as compared to the control group was similar to findings of other studies [3,4]. LP group also showed decreased pain scores at above-mentioned times without any significant difference. However, only in LP group, pain scores at $24 \mathrm{~h}$ were lower than postoperative pain scores. It was expected that BP or LP should have displayed significant differences at least compared to the control group. It is suggested that non-significant differences might be caused by minimum tissue trauma approach in the current study.

It is well documented that there is no gold standard to evaluate pain in animals but measurements of some biochemical parameters may help to objectively evaluate the presence and severity of postoperative pain [7,11]. Environmental changes, anaesthesia and surgical procedures comprise a response originated from the hypothalamic - pituitary - adrenal axis and the most important indicators of surgical stress are the changes 
in the blood levels of the cortisol hormone [11,12,29]. Devitt et al. [9] reported that levels of cortisol increased until $2 \mathrm{~h}$ after standard or laparoscopic OHE in bitches, whereas Yilmaz et al. [31] stated that the increment of the concentrations of cortisol was observed for $2.5 \mathrm{~h}$ in dogs following standard OHE. Clearly, BP has rapidly decreased the concentration of cortisol which reaches its level 30 minutes after the end of surgery [16]. The present study showed that cortisol levels were elevated in all groups and this finding was consistent with other reports $[9,16,31]$. On the other hand, the concentrations of cortisol rapidly decreased in BP and LP groups with respect to the control group. It is suggested that rapidly reduced cortisol levels might be attributed to the analgesic effects of both BP and LP.

\section{CONCLUSION}

In conclusion, OHE surgery performed in dogs, from a small ventral midline incision and in a short duration of time, with minimal trauma to abdominal organs, is closely associated with decreased postoperative pain. This study reported for the first time the effect of sprayed intraperitoneal or incisional LP on postoperative pain scores of ovariohysterectomised dogs and indicates that LP can be a good alternative to other local anesthetics.

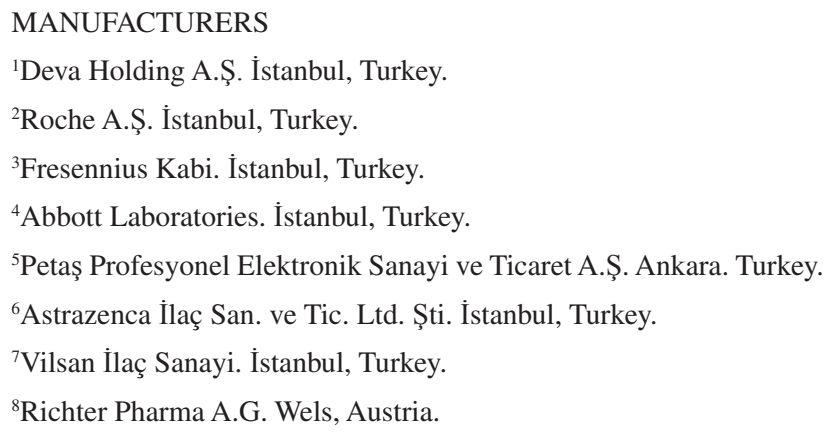

Funding. Financial assistance for this research was provided by Afyon Kocatepe University Research Fund (project number AKU, BAPK 14.VF.13).

Ethical approval. The study was approved by the animal local Ethics Committee (permission number AKU-HADYEK 49533702 / 37), Afyon Kocatepe University.

Declaration of interest. The authors report no conflicts of interest. The authors alone are responsible for the content and writing of the paper.

\section{REFERENCES}

1 Bartel A.K., Campoy L., Martin-Flores M., Gleed R.D., Walker K.J., Scanapico C.E. \& Reichard A.B. 2016. Comparison of bupivacaine and dexmedetomidine femoral and sciatic nerve blocks with bupivacaine and buprenorphine epidural injection for stifle arthroplasty in dogs. Veterinary Anaesthesia and Analgesia. 43: 435-443.

2 Benito J., Monteiro B.P., Beaudry F., Lavoie A.M., Lascelles B.D.X. \& Steagall P.V. 2016. Pharmacokinetics of bupivacaine after intraperitoneal administration to cats undergoing ovariohysterectomy. American Journal of Veterinary Research. 77(6): 641-645.

3 Campagnol D., Teixeira-Neto F.J., Monteiro E.R., Restitutti F. \& Minto B.W. 2012. Effect of intraperitoneal or incisional bupivacaine on pain and the analgesic requirement after ovariohysterectomy in dogs. Veterinary Anaesthesia and Analgesia. 39(4): 426-430.

4 Carpenter R.E., Wilson D.V. \& Evans A.T. 2004. Evaluation of intraperitoneal and incisional lidocaine or bupivacaine for analgesia following ovariohysterectomy in the dog. Veterinary Anaesthesia and Analgesia. 31(1): 46-52.

5 Casati A. \& Putzu M. 2005. Bupivacaine, levobupivacaine and ropivacaine: Are they clinically different? Best Practice \& Research: Clinical Anaesthesiology. 19(2): 247-268.

6 Cerasoli I., Tutunaru A., Cenani A., Ramirez J., Detilleux J., Balligand M. \& Sandersen C. 2017. Comparison of clinical effects of epidural levobupivacaine morphine versus bupivacaine morphine in dogs undergoing elective pelvic limb surgery. Veterinary Anaesthesia and Analgesia. 44: 337-345.

7 Conzemius M.G., Hill C.M., Sammarco J.L. \& Perkowski S.Z. 1997. Correlation between subjective and objective measures used to determine severity of postoperative pain in dogs. Journal of the American Veterinary Medical Association. 210(11): 1619-1622.

8 Costa G.L., Nastasi B., Spadola F., Leonardi F. \& Interlandi C. 2019. Effect of levobupivacaine, administered intraperitoneally, on physiological variables and on intrasurgery and postsurgery pain in dogs undergoing ovariohysterectomy. Journal of Veterinary Behavior. 30: 33-36. 
9 Devitt C.M., Cox R.E. \& Hailey J.J. 2005. Duration, complications, stress, and pain of open ovariohysterectomy versus a simple method of laparoscopic-assisted ovariohysterectomy in dogs. Journal of the American Veterinary Medical Association. 227(6): 921-927.

10 Foster R.H. \& Markham A. 2000. Levobupivacaine: a review of its pharmacology and use as a local anaesthetic. Drugs. 59(3): 551-579.

11 Fox S.M., Mellor D.J., Firth E.C., Hodge H. \& Lawoko C.R.O. 1994. Changes in plasma cortisol concentrations before, during and after analgesia, anaesthesia and anaesthesia plus ovariohysterectomy in bitches. Research in Veterinary Science. 57(1): 110-118.

12 Frank L.A., Kunkle G.A. \& Beale K.M. 1992. Comparison of serum cortisol concentration before and after intradermal testing in sedated and nonsedated dogs. Journal of the American Veterinary Medical Association. 200(4): 507-510.

13 Groban L., Deal D.D., Vernon J.C., James R.L. \& Butterworth J. 2001. Cardiac resuscitation after incremental overdosage with lidocaine, bupivacaine, levobupivacaine, and ropivacaine in anesthetized dogs. Anesthesia \& Analgesia 92(1): 37-43.

14 Guerrero K.S.K., Campagna I., Bruhl-Day R., Hegamin-Younger C. \& Guerrero T.G. 2016. Intraperitoneal bupivacaine with or without incisional bupivacaine for postoperative analgesia in dogs undergoing ovariohysterectomy. Veterinary Anaesthesia and Analgesia. 43: 571-578.

15 Hardie E.M., Hansen B.D. \& Carroll G.S. 1997. Physiological measurements after ovariohysterectomy in dogs: what's normal. Applied Animal Behaviour Science. 51: 111-128.

16 Kim Y.K., Lee S.S., Suh E.H., Lee L., Lee H.C., Lee H.J. \& Yeon S.C. 2012. Sprayed intraperitoneal bupivacaine reduces early postoperative pain behavior and biochemical stress response after laparoscopic ovariohysterectomy in dogs. Veterinary Journal. 191(2): 188-192.

17 Korkmaz M. \& Saritas K. 2013. Comparison of the Eff ects of Epidurally Administered Bupivacaine and Levobupivacaine in Conscious Dogs. Acta Scientiae Veterinariae. 41: 1-9.

18 Lascelles B.D.X., Rausch-Derra L.C., Wofford J.A. \& Huebner M. 2016. Pilot, randomized, placebocontrolled clinical field study to evaluate the effectiveness of bupivacaine liposome injectable suspension for the provision of post-surgical analgesia in dogs undergoing stifle surgery. BMC Veterinary Research. 12: 168.

19 Lemke K.A., Runyon C.L. \& Horney B.S. 2002. Effects of preoperative administration of ketoprofen on anesthetic requirements and signs of postoperative pain in dogs undergoing elective ovariohysterectomy. Journal of the American Veterinary Medical Association. 221(9): 1268-1275.

20 Leone S., Di Cianni S., Casati A. \& Fanelli G. 2008. Pharmacology, toxicology, and clinical use of new long acting local anesthetics, ropivacaine and levobupivacaine. Acta Biomed l'Ateneo Parm. 79(2): 92-105.

21 Merema D.K., Schoenrock E.K., Boedec K.L. \& McMichael M.A. 2017. Effects of a transdermal lidocaine patch on indicators of postoperative pain in dogs undergoing midline ovariohysterectomy. Journal of the American Veterinary Medical Association. 250(10): 1140-1147.

22 Michelsen J., Heller J., Wills F. \& Noble G. 2012. Effect of surgeon experience on postoperative plasma cortisol and C-reactive protein concentrations after ovariohysterectomy in the dog: A randomised trial. Australian Veterinary Journal. 90(12): 474-478.

23 Odete O. \& Smith L.J. 2013. A comparison of epidural analgesia provided by bupivacaine alone, bupivacaine + morphine, or bupivacaine + dexmedetomidine for pelvic orthopedic surgery in dogs. Veterinary Anaesthesia and Analgesia. 40(5): 527-536.

24 Olson P.N. \& Johnston S.D. 1993. New developments in small animal population control. Journal of the American Veterinary Medical Association. 202(6): 904-909.

25 Pollari F.L., Bonnett B.N., Bamsey S.C., Meek A.H. \& Allen D.G. 1996. Postoperative complications of elective surgeries in dogs and cats determined by examining electronic and paper medical records. Journal of the American Veterinary Medical Association. 208(11): 1882-1886.

26 Saritas Z.K., Korkmaz M. \& Ylmaz O. 2014. The effect of intravenously given dexketoprofen trometamol on postoperative pain in ovariohysterectomized dogs. Eurasian Journal of Veterinary Sciences. 30: 5-10.

27 Saritas Z.K., Saritas T.B., Pamuk K., Korkmaz M., Yaprakci M.V., Yilmaz O. \& Demirkan I. 2015. Evaluation of preemptive dexketoprofen trometamol effect on blood chemistry, vital signs and postoperative pain in dogs undergoing ovariohysterectomy. Bratislava Medical Jorunal. 116(3): 191-195. 
28 Shaikh S.I., Revur L.R. \& Mallappa M. 2017. Comparison of epidural clonidine and dexmedetomidine for perioperative analgesia in combined spinal epidural anesthesia with intrathecal levobupivacaine: a randomized controlled doubleblind study. Anesth Essays Res. 11: 503-507.

29 Skovira E.J., Behrend E.N., Martin L.G., Palmer L.E., Kemppainen R.J. \& Lee H.P. 2017. Effect of laparotomy on the pituitary-adrenal axis in dogs. American Journal of Veterinary Research. 78(8): 919-925.

30 Tsai T.Y., Chang S.K., Chou P.Y. \& Yeh L.S. 2013. Comparison of postoperative effects between lidocaine infusion, meloxicam, and their combination in dogs undergoing ovariohysterectomy. Veterinary Anaesthesia and Analgesia. 40(6): 615-622.

31 Yilmaz O., Korkmaz M., Jaroszewski J.J., Yazici E., Ulutas E. \& Saritas Z.K. 2014. Comparison of flunixin meglumine and meloxicam influence on postoperative and oxidative stress in ovariohysterectomized bitches. Polish Journal of Veterinary Science. 17(3): 493-499. 